continued in the mistaken belief that shock is due to hypovolaemia. Anaesthetists and surgeons need to be aware that such allergic reactions can occur.

1 Ring J, Messmer K. Incidence and severity of anaphylactoid reactions to colloid volume substitutes. Lancet 1977;1:466-9. 2 Laxenaire MC, Charpentier C, Feldman L. [Anaphylactoid reactions to colloid plasma substitutes: incidence, risk factors, mechanisms. A French multicentre prospective study](French). Ann Fr Anesth Reanim 1994;13:301-10.
Keywords: plasma expanders; allergic reactions; hypotension; adverse drug reaction; Gelofusine

\title{
Diabetic ketoacidosis and clozapine
}

\author{
Dawn Ai, T A Roper, J A Riley
}

Clozapine is an antipsychotic drug used for the management of schizophrenia. Due to its sideeffects, it is reserved for patients unresponsive to, or intolerant of the conventional antipsychotic drugs. ${ }^{1}$ Cases of hyperglycaemia have been reported as a rare complication of clozapine. We report a case of diabetic ketoacidosis associated with the use of clozapine.

\section{Case report}

A 30-year-old Afro-Caribbean man with paranoid schizophrenia was admitted under the care of the medical team with severe vomiting for 2-3 days. He had a history of mild asthma and hidradenitis suppurativa but no previous or family history of diabetes. He had been treated previously by the psychiatrists but had not responded to conventional doses of neuroleptics. Therefore, five months prior to this admission, he had been started on clozapine. The dose was built up gradually over the subsequent weeks to $150 \mathrm{mg}$ bid. His only other treatment was minocycline for hidradenitis suppurativa.

On examination he was apyrexial and clinically dehydrated but otherwise normal, with a normal full blood count. Urea and electrolytes revealed sodium to be low at 124 $\mathrm{mmol} / \mathrm{l}$, potassium $3.8 \mathrm{mmol} / \mathrm{l}$, urea and creatinine raised at $8.0 \mathrm{mmol} / 1$ and $152 \mu \mathrm{mol} / \mathrm{l}$, respectively, amylase normal and glucose raised at $24.9 \mathrm{mmol} / 1$. Urinalysis revealed copious ketones and arterial blood gases showed $\mathrm{pH}$ 7.27, $\mathrm{pCO}_{2} 3.2 \mathrm{kPa}, \mathrm{pO}_{2} 13.4 \mathrm{kPa}$ and bicarbonate $11.2 \mathrm{mmol} / \mathrm{l}$. Chest $\mathrm{X}$-ray and electrocardiogram were normal and toxic screen for salicylate and paracetamol was negative. A diagnosis of diabetic ketoacidosis was made and the patient was treated with a sliding scale regime of insulin, and intravenous fluid rehydration with potassium supplements.

Over the next 24 hours his blood sugar stabilised and his urea and electrolytes improved. Unfortunately the patient's psychiatric condition complicated his management. He had no insight into his illness, and would not accept his insulin injections or BM stixs monitoring. After liaising with his psychiatrists it was
3 Watkins J, Wild G, Appleyard TN, Hardy G. Complement activation by polystarch and gelatin volume expanders. $L a n-$ cet 1990;335:233.

4 Young K. Hypotension from the interaction of ACE inhibitors with stable plasma protein solution. (letter) Anaesthesia 1993;48:356.
St James's University Hospital, Leeds, West $\mathrm{D} \mathrm{Ai}$

T A Roper

Correspondence to Dr Dawn $\mathrm{Ai}$, SHO Anaesthetics, Department of Anaesthetics, The Royal Infirmary of Edinburgh, Lauriston Place, Edinburgh EH3 9YW, Scotland, UK

Accepted 19 November 1997

\section{Side-effects of clozapine}

Drowsiness, sedation, headache, dry mouth, hypersalivation, convulsions, neuroleptic malignant syndrome, tachycardia, postural hypotension, arrhythmias, pericarditis, myocarditis, cholestasis, pancreatitis, agranulocytosis.

Box 1

decided that clozapine should be stopped in view of its association with hyperglycaemia. Clozapine was substituted by olanzapine, another of the newer agents for the treatment of schizophrenia. We also sought advice from a consultant diabetic physician, who suggested maximum doses of an oral hypoglycaemic agent. The patient was controlled on gliclazide $160 \mathrm{mg}$ bid. Over the next two weeks his blood sugar remained stable at around $7-11 \mathrm{mmol} / 1$ and he was discharged back to the psychiatrists. He remains on gliclazide $80 \mathrm{mg}$ bid 8 months after his initial presentation.

\section{Discussion}

Clozapine is used for people with schizophrenia who have had an inadequate response to at least two standard neuroleptics (Guide to the clozapine patient monitoring service, Sandoz Pharmaceuticals). It has an unusual neuropharmacological profile, with a low affinity for dopamine D2 receptors (unlike other antipsychotic drugs), but a high affinity for D4 and 5-HT2 receptors. ${ }^{2}$ It has good efficacy and causes fewer extrapyramidal side-effects than the conventional neuroleptics. About $30 \%$ of patients respond after 6 weeks, $49 \%$ by 6 months and $61 \%$ by a year (Information fact sheet on clozaril, Sandoz Pharmaceuticals). However, its side-effects (box 1) prevent it being used as a first-line treatment. The major complication is agranulocytosis which occurs in $0.8 \%$ of treated patients. ${ }^{3}$ Thus, initiation of the drug must be in hospital with close monitoring of the blood counts.

There are eight other cases of hyperglycaemia associated with clozapine reported in the 
literature. ${ }^{4-8}$ At least seven out of nine cases (including the present case) were patients of Afro-Caribbean origin ${ }^{4-68}$ (one case did not specify the ethnic origin ${ }^{7}$ ). In four cases there was a family history of diabetes. ${ }^{5-8}$ In two cases the patients were known to have established type II diabetes mellitus, well controlled on oral hypoglycaemic agents. After commencing clozapine their hyperglycaemia worsened, both requiring insulin treatment. In eight out of nine cases, including our own, ${ }^{4-68}$ the patients were taking other drugs concurrently and it is difficult to know whether those drug combinations may have impaired glucose metabolism. The fourth case ${ }^{7}$ involved a patient treated with clozapine as monotherapy and it is clear that clozapine alone was associated with the development of diabetic ketoacidosis.

In all the cases reported hyperglycaemia occurred early, about 4-8 weeks after the initiation of clozapine. In our case, it took 5 months before a diagnosis of ketoacidosis was made. However subsequent blood result showed a marked increase in HbAlc (11\%), suggesting glucose tolerance had been impaired prior to presentation. In six out of nine cases discontinuation of clozapine led to the resolution of hyperglycaemia, though the time required for normoglycaemia to be achieved varied. In two cases the patients were continued on clozapine and still require treatment for raised sugars. In our case, 8 months after stopping clozapine, the patient still requires an oral hypoglycaemic agent. This suggests that clozapine may have unmasked latent diabetes.

\section{Conclusion}

Our case demonstrated that the drug clozapine may be associated with the development of diabetic ketoacidosis. It seems that people of Afro-Caribbean ethnic origin may be more susceptible to this side-effect. Little is known

1 Anon. Update of clozapine. Med Lett Drugs Ther 1993;35:16-8.

2 Yakeley JW, Murray RM. Schizophrenia. Med Int Psychiatry 1996;24:2.

3 Atkin K, Kendall F, Gould D, Freeman H, Lieberman J O'Sullivan D. Neutropenia and agranulocytosis in patients receiving clozapine in the UK and Ireland. $B r \mathcal{F}$ Psychiatry 1996;169:483-8.

4 Kamran A, Doraiswamy PM, Jane JL, Hammet EB, Dunn L. Severe hyperglycaemia associated with high dose of clozapine. Am $\mathcal{F}$ Psychiatry 1994;151:1395.

\section{Drugs known to cause \\ hyperglycaemia/diabetes}

Amoxapine, beta-blockers, calcium channel

blockers, clonidine, corticosteroids, diazoxide, diuretics, isoniazid, oral contraceptives, phenothiazines, salbutamol, somatostatin, theophylline

Box 2

\section{Learning points}

- clozapine is an atypical antipsychotic drug used for the treatment of schizophrenia

- its side-effects, in particular agranulocytosis, restrict its use to patients unresponsive to or intolerant of conventional treatment

- diabetic ketoacidosis is associated with clozapine

Box 3

about the effect of clozapine on glucose metabolism and why black people should be at particular risk. Whether clozapine directly induces hyperglycaemia or merely acts as a trigger in people with a predisposition to diabetes remains unresolved. More research is needed to answer these questions. It is also important that physicians and psychiatrists are aware of the danger of diabetic ketoacidosis with clozapine therapy, especially in patients of Afro-Caribbean origin, those with a family history of diabetes and, of course, established diabetics. In these patients, blood glucose levels should be closely monitored.

Keywords: adverse drug reaction; clozapine; ketoacidosis; Afro-Caribbeans; diabetes

We thank Dr AV Simmons for his permission to write about this case and his suggestions and advice.

5 Koval MS, Rames LJ, Christie S. Diabetic ketoacidosis associated with clozapine treatment. Am $\mathcal{F}$ Psychiatry 1994; 151:1520-1.

6 Peterson GA, Byrd SL. Diabetic ketoacidosis from clozapine with lithium cotreatment. Am $\mathcal{f}$ Psychiatry 1996;153: ine with

7 Kostakoglu AE, Yazici KM, Erbas T, Guvener N. Ketoacidosis as a side-effect of clozapine: a case report. Acta Psychiatr Scand 1996;93:217-8.

8 Popli AP, Konicki E, Jurjus G, Fuller M, Jaskiw G. Clozapine and associated diabetes mellitus. $\mathcal{f}$ Clin Psychiatry 1997;58:3. 